\title{
Pengaruh Pelatihan terhadap Kinerja Pegawai pada Puskesmas Simpang Kawat Kota Jambi
}

\author{
M. Alhudhori ${ }^{I}$ \\ Fakultas Ekonomi Universitas Batanghari, Program Studi Manajemen ${ }^{l}$
}

\begin{abstract}
This research entitled "Training Effect Against Employee Performance Of Simpang Kawat Health Center In Jambi City ". Objectives of this research are to know the training activity, and performance of the Employee. Survei was used as method of this research. The data was collected by using quetioner. For analizing data, verificative method was used to proof that training influence upon performance of the employee. Influence of training upon the employee performance were analized by means of simply regression. The result of this research shows that according to the employee training activity and performance of the Simpang Kawat Health Center were good. Moreover, training have influence significantly upon the employee performance.
\end{abstract}

Keywords : Training and performance

\section{PENDAHULUAN}

Manajemen sumber daya manusia mempunyai kekhususan dibandingkan dengan manajemen sumber daya lain, karena yang dikelola adalah manusia, maka keberhasilan atau kegagalan manajemen sumber daya manusia akan mempunyai dampak yang sangat luas.

Mengingat pentingnya sumber daya manusia di dalam suatu instansi maka tenaga kerja harus diperhatikan potensi sedemikian rupa, sehingga dapat dimanfaatkan agar dapat berdaya guna. Jika dilihat dari perspektif manajemen sumber daya manusia disebutkan bahwa aspek yang tidak kalah pentingnya dari aspek yang lain dalam peningkatan kinerja adalah aspek pengembangan, termasuk salah satunya adalah program pelatihan.

Pelatihan merupakan salah satu upaya untuk meningkatkan kemampuan pegawai dalam mengemban tugas yang telah diberikan agar pegawai semakin terampil dan mampu melaksanakan tanggung jawab yang telah digariskan oleh organisasi. Hal ini sejalan dengan Simamora (2006:7) Pelatihan dapat meningkatkan kualitas dan kuantitas kinerja. Sedarmayanti (2009:52) menyatakan bahwa faktor yang mempengaruhi kinerja adalah pelatihan. Pelatihan dalam bentuk yang kompleks diberikan untuk membantu pegawai memperoleh pengetahuan yang akan meningkatkan kinerja mereka dan akan membantu lembaga mencapai tujuannya.

Suatu organisasi yang menjadi objek penelitian ini yaitu Puskesmas Simpang Kawat Kota Jambi.
Tabel 1. Jumlah Pegawai Pada Puskesmas

Simpang Kawat Kota Jambi 2013-2018

\begin{tabular}{cccccc}
\hline Tahun & \multicolumn{3}{c}{$\begin{array}{c}\text { Jumlah Pegawai } \\
\text { (Orang) }\end{array}$} & Total & $\begin{array}{c}\text { Persentase } \\
(\%)\end{array}$ \\
& PNS & PTT & TKS & & \\
\hline 2013 & 16 & 12 & 8 & 34 & - \\
2014 & 14 & 11 & 6 & 31 & $(9,67)$ \\
2015 & 12 & 10 & 6 & 28 & $(10,71)$ \\
2016 & 15 & 13 & 7 & 34 & 17,64 \\
2017 & 17 & 20 & 6 & 43 & 20,93 \\
$2018^{*}$ & 17 & 21 & 6 & 44 & 2,27 \\
\hline
\end{tabular}

*Sampai bulan Mei

Sumber : Puskesmas Simpang Kawat Kota Jambi 2018

Keterangan :

$$
\begin{array}{ll}
\text { PNS } & =\text { Pegawai Negeri Sipil } \\
\text { PTT } & =\text { Pegawai Tidak Tetap } \\
\text { TKS } & =\text { Tenaga Kerja Sukarela }
\end{array}
$$

Berdasarkan tabel 1 di atas terlihat jelas bahwa pegawai pada puskesmas simpang kawat 6 tahun terakhir berfluktuasi, Pada tahun 2014 mengalami penurunan dari 34 orang di tahun 2013 menjadi 31 orang sedangkan di tahun 2015 mengalami penurunan kembali dari 31 orang menjadi 28 orang. Namun di tahun 2016 mengalami kenaikan dari 28 orang menjadi 34 orang dan terjadi kenaikan kembali di tahun 2017 sebanyak 9 orang menjadi 43 orang dan ditahun 2018 sampai bulan Mei naik dari 43 orang menjadi 44 orang.

Puskesmas Simpang Kawat Kota Jambi juga telah memberikan berbagai pelatihan terhadap pegawai. Pelatihan yang diikuti oleh pegawai tersebut diharapkan dapat meningkatkan kinerja pada puskesmas simpang kawat tersebut. Namun pada kenyataannya 
pelatihan yang diberikan belum optimal dan jumlah pegawai yang mengikuti pelatihan setiap tahun masih terlalu kecil dibanding dengan jumlah pegawai yang ada sehingga kinerja yang dihasilkan belum optimal.

Berdasarkan identifikasi masalah di atas, maka masalah yang dapat dirumuskan berkaitan dengan pelatihan dan kinerja di Puskesmas Simpang Kawat Kota Jambi sebagai berikut :

"Apakah pelatihan mempunyai pengaruh terhadap kinerja pegawai pada Puskesmas Simpang Kawat Kota Jambi”.

Berdasarkan rumusan masalah penelitian maka hipotesisnya adalah " Pelatihan berpengaruh terhadap kinerja pegawai pada Puskesmas Simpang Kawat Kota Jambi”.

Adapun tujuan dari penelitian ini adalah : "Untuk mengetahui pengaruh pelatihan terhadap kinerja pegawai pada Puskesmas Simpang Kawat Kota Jambi”.

\section{METODE PENELITIAN}

Dalam penelitian ini, terdapat dua variabel yang akan dianalisis yang terdiri dari :

a. Variabel bebas (independent variabel) yaitu Variabel Pelatihan (X).

Pelatihan merupakan serangkaian aktifitas yang diracang untuk meningkatkan keahliankeahlian, pengetahuan, pengalaman ataupun perubahan sikap seorang individu. Dimana menurut Simamora (2004:124) menjelaskan ada 6 indikator pelatihan yaitu memperbaiki kinerja, keahlian para pegawai sejalan dengan kemajuan teknologi, mengurangi waktu pembelajaran bagi para pegawai baru agar kompeten dalam bekerja, membantu memecahkan masalah operasional, mempersiapkan pegawai untuk promosi dan mengorientasi pegawai terhadap promosi.

b. Variabel Terikat (dependent variabel) yaitu Variabel Kinerja (Y)

Kinerja hasil kerja secara kualitas dan kuantitas yang dicapai oleh seseorang pegawai dalam melaksanakan tugasnya sesuai dengan tanggung jawab yang diberikan kepadanya. Menurut Kaswan (2012:187) ada indikator utama sebagai dasar untuk mengukur tingkat kinerja seseorang ataupun organisasi yaitu kualitas, kuantitas, ketepatan waktu, efektifitas biaya, kebutuhan untuk supervisi dan dampak interpersonal.

Dalam penelitian ini penulis menggunakan data primer dan data sekunder. Data primer diperoleh menggunakan metode survei dengan teknik pengumpulan data berupa wawancara dan kuisioner. Kemudian data sekunder diperoleh berupa data internal Puskesmas Simpang Kawat Kota Jambi.

Jenis data yang digunakan yaitu data kualitatif dengan menyebar kuisioner yang alternatif jawabannya telah disediakan kepada responden sementara kuantitatif menggunakan Metode Likert Summated Rating dengan diberi skor tertentu.

\begin{tabular}{lc}
\hline \multicolumn{1}{c}{ JAWABAN } & BOBOT \\
\hline Sangat Baik & 5 \\
Baik & 4 \\
Kurang Baik & 3 \\
Tidak Baik & 2 \\
Sangat Tidak Baik & 1 \\
\hline
\end{tabular}

Dengan demikian Kuisioner dalam penelitian ini merupakan kuisioner tertutup karena alternatif jawaban telah disiapkan oleh penulis sehingga lebih mudah untuk ditabulasi.

Dalam menganalisis data, hipotesis dijelaskan menggunakan metode verifikatif dengan analisis statistik regresi linier sederhana. Aplikasi dari penggunaan alat statistik inferensial tersebut dilakukan dengan menggunakan program komputer SPSS Ver 20,0. Adapun tehapan analisa data tersebut sebagai berikut :

a. Menentukan Variabel penelitian di Puskesmas Simpang Kawat Kota Jambi terdiri atas :

1) Pelatihan (X) yang didasarkan pada hasil kuisioner setelah ditabulasikan

2) Kinerja Pegawai (Y) yang diasarkan pada hasil kuisioner.

b. Regresi Linear Sederhana, untuk mengetahui pengaruh antara variabel $\mathrm{X}$ terhadap variabel $\mathrm{Y}$ atau merupakan jawaban dari Hipotesis, yaitu dengan menggunakan rumus :

$$
\begin{array}{ll} 
& Y=\alpha+b X \\
\text { Dimana: } & \mathrm{Y}=\text { Kinerja Pegawai } \\
& \mathrm{X}=\text { Pelatihan } \\
& \alpha=\text { Konstanta } \\
& \mathrm{b}=\text { Koefisien Regresi }
\end{array}
$$

c. Koefisien Determinasi yang dapat dilihat dari nilai $\mathrm{R}$ Square yang menunjukan seberapa besar variabel independen dapat menjelaskan variabel dependen. Semakin tinggi nilai $\mathrm{R}$ Square maka semakin baik model regresi yang digunakan.

d. Pengujian hipotesis penelitian menggunakan alat statistik berupa uji $t$ untuk menguji apakah variabel bebas (Pelatihan) mempunyai pengaruh yang signifikan terhadap variabel terikat (Kinerja). Bentuk 
Pengujian dalam penelitian ini sebagai berikut :

$\mathrm{H}_{0} \quad$ : Pelatihan berpengaruh terhadap kinerja pegawai

$\mathrm{H}_{1}$ : Pelatihan tidak berpengaruh terhadap kinerja pegawai

Berdasarkan pengujian uji t, akan diperoleh hasil $t$ hitung. Kemudian dibandingkan dengan t table (lampiran)

- Bila $\mathrm{t}$ hitung $>\mathrm{t}$ tabel, maka $\mathrm{H}_{0}$ ditolak dan $\mathrm{H}_{1}$ diterima

- Bila $\mathrm{t}$ hitung $<\mathrm{t}$ tabel, maka $\mathrm{H}_{0}$ diterima dan $\mathrm{H}_{1}$ ditolak

Pengujian hipotesis dilakukan dengan dua arah pada taraf signifikan yang digunakan $=5 \%$ dan $\mathrm{dk}=\mathrm{n}-\mathrm{k}-1$. Bila $\mathrm{H}_{0}$ diterima maka hipotesis penelitian benar.

\section{HASIL DAN PEMBAHASAN \\ Regresi Linier Sederhana}

Untuk menjawab hipotesis yang diajukan dalam penelitian ini mengenai pengaruh pelatihan terhadap kinerja pegawai pada Puskesmas Simpang Kawat Kota Jambi digunakan analisis regresi linier sederhana. Untuk memenuhi syarat data yang digunakan sekurang-kurangnya mempunyai tingkat pengukuran interval. Data yang dikumpulkan dari kuisioner yang mempunyai skala pengukuran ordinal, terlebih dahulu ditransformasikan menjadi skala interval menggunakan Method of Succesive Interval (MSI).

Selanjutnya data tersebut diolah menggunakan program SPSS 20.0 for windows yang menghasilkan data estimasi regresi berikut ini :

Dari tabel 2 dapat diperoleh persamaan regresi linier sederhana sebagai berikut :

$\mathrm{Y}=2,085+0,281 \mathrm{X}$

Dimana :

$\mathrm{Y}=$ Kinerja

$\mathrm{X}=$ Pelatihan

Persamaan regresi yang terbentuk dapat diartikan dengan nilai konstanta 2,085 menunjukan skor rata-rata kinerja pegawai Puskesmas Simpang Kawat Kota Jambi. Nilai koefisien regresi pelatihan (X) sebesar 0,281 menunjukan bahwa jika skoe pelatihan naik satu satuan akan diikuti oleh peningkatan skor kinerja. Jadi semakin baik pelatihan (X) semakin tinggi kinerja pegawai Puskesmas Simpang Kawat Kota Jambi (Y).

Tabel 2. Hasil Estimasi Regresi

Coefficients $^{\mathrm{a}}$

\begin{tabular}{|c|c|c|c|c|c|c|}
\hline \multirow{2}{*}{\multicolumn{2}{|c|}{ Model }} & \multicolumn{2}{|c|}{ Unstandardized Coefficients } & Standardized & \multirow[t]{2}{*}{$\mathrm{t}$} & \multirow[t]{2}{*}{ Sig. } \\
\hline & & B & Std. Error & Beta & & \\
\hline \multirow{2}{*}{1} & (Constant) & 2,085 & ,228 & \multirow[b]{2}{*}{ 483 } & 9,137 & , 000 \\
\hline & Pelatihan & ,281 & ,084 & & 3,359 & ,002 \\
\hline
\end{tabular}

a. Dependent Variable: Kinerja (Y)

Tabel 3. Koefisien Determinasi Model Summary

\begin{tabular}{|l|r|r|r|r|}
\hline Model & \multicolumn{1}{|c|}{ R } & \multicolumn{1}{c|}{ R Square } & \multicolumn{1}{c|}{$\begin{array}{c}\text { Adjusted R } \\
\text { Square }\end{array}$} & \multicolumn{1}{c|}{ Std. Error of the Estimate } \\
\hline 1 &, $483^{\mathrm{a}}$ &, 234 &, 213 &, 22691 \\
\hline
\end{tabular}

a. Predictors: (Constant), Pelatihan, $\mathrm{X}$

b. Dependent Variable :Y

\section{Koefisien Determinasi}

Dari tabel 3 dapat dilihat bahwa nilai $\mathrm{R}$ atau korelasi sebesar 0,483 atau $48,3 \%$ merupakan besarnya hubungan antara variabel pelatihan terhadap variabel kinerja. Selanjutnya diperkuat dengan nilai R Square atau Koefisien Determinasi sebesar 0,234 menunjukan keeratan hubungan variabel pelatihan dengan variabel kinerja pegawai. Jadi pelatiahn dapat menjelaskan atau mempengaruhi kinerja pegawai pada Puskesmas Simpang Kawat Kota Jambi sebesar 23,4 \%, sedangkan $76,6 \%$ lain yang tidak dipengaruhi oleh variabel yang tidak di teliti dalam penelitian ini.

\section{Pengujian Hipotesis (Uji t)}

Pengujian ini dilakukan untuk mempengaruhi tingkat signifikan dari pengaruh variabel bebas secara individual terhadap variabel terikat 
Tabel 4. Uji Statistik t

Coefficients $^{\mathrm{a}}$

\begin{tabular}{|rl|r|r|r|r|r|}
\hline \multirow{2}{*}{ Model } & \multicolumn{2}{|c|}{ Unstandardized Coefficients } & \multicolumn{1}{c|}{$\begin{array}{c}\text { Standardized } \\
\text { Coefficients }\end{array}$} & \multirow{2}{*}{ Sig. } & \\
\cline { 3 - 5 } & \multicolumn{2}{|c|}{ B } & \multicolumn{1}{c|}{ Std. Error } & \multicolumn{1}{c|}{ Beta } & & \\
\hline \multirow{2}{*}{1} & (Constant) & 2,085 &, 228 & & 9,137 &, 000 \\
& Pelatihan &, 281 &, 084 &, 483 & 3,359 &, 002 \\
\hline
\end{tabular}

a. Dependent Variable: Kinerja (Y)

Berdasarkan tabel 4 di atas dapat dilihat hasil uji t dan tingkat signifikan dari variabel pelatihan (X) sebagai berikut :

a. Variabel pelatihan mempunyai pengaruh yang sangat signifikan terhadap variabel kinerja karena pelatihan mempunyai tingkat signifikan 0,05 yaitu $0,002(0,002<0,05)$.

b. $\mathrm{t}_{\text {hitung }} 3,359>\mathrm{t}_{\text {tabel }} 2,02619$ untuk $\alpha=0,05$ sehingga dapat diambil keputusan untuk menolak $\mathrm{H}_{1}$ dan menerima $\mathrm{H}_{0}$, hal ini bearti berdasarkan penelitian terdapat pengaruh positif yang sgnifikan dari pelatihan terhadap kinerja pegawai pada Puskesmas Simpang Kawat Kota Jambi.

\section{SIMPULAN}

Berdasarkan hasil penelitian dan pembahasan yang telah dikemukakan sebelumnya, maka kesimpulan penelitian ini adalah :

1. Pelatihan dan Kinerja pegawai pada Puskesmas Simpang Kawat Kota Jambi baik.

2. Pelatihan berpengaruh positif dan signifikan terhadap kinerja pegawai pada Puskesmas Simpang Kawat Kota Jambi.

\section{DAFTAR PUSTAKA}

Arikunto, Suharsimi. (2014), Prosedur Penelitian Suatu Pendekatan Praktek, cetakan 15, Jakarta : Rineka Cipta

Barthos, Basir. (2004), Manajemen Sumber Daya Manusia, Suatu Pendekatan Praktek, Jakarta : Bumi Aksara

Handoko, T. Hani. (2011), Manajemen, Jakarta : PT. Ghalia Indonesia

Hasibuan, Melayu S.P.(2009), Manajemen Sumber Daya Manusia, Jakarta : Toko Gunung Agung

Kaswan. (2012), Manajemen Sumber Daya Manusia Untuk Keunggulan Berorganisasi, Yoyakarta : Graha Ilmu

Mangkunegara. (2009), Manajemen Sumber Daya Manusia Perusahaan, Bandung : Rosdakarya
Mangkuprawira, TB. Sjafri. (2004), Manajemen SDM Strategik, Jakarta : PT. Ghalia Indonesia

Nawawi, Hadari. (2011), Manajemen Sumber Daya Manusia, Yogyakarta : Gadja Mada University Press

Priansa, Donni, Juni. (2018), Perencanaa dan Pengembangan SDM, Bandung : Alfabeta

Rivai, Veithzal.(2009), Kepemimpinan dan Perilaku Organisasi, Jakarta : PT. Raja Grafindo Persada

Sedarmayanti. (2009), Sumber Daya Manusia dan Kinerja, Bandung : CV. Mandar Maju

Siagian, Sondang P. (2009), Manajemen Sumber Daya Manusia, Edisi Ke-2, Yogyakarta : Bumi

Simamora. (2006), Manajemen Kepegawaian, Jakarta : Ghalia

Sugiyono. (2012), Metode Penelitian Bisnis,Bandung : Alfabeta

Supardi. (2013). Aplikasi Statistic Dalam Penelitian, Jakarta: Change Publication

Suwanto. (2011), Manajemen Sumber Daya Manusia, Bandung : CV. Alfabeta

Syekh, Saiyid. (2011), Pengantar Statistic Ekonomi dan Social, Jakarta : Gaung Persada Press

Umar, Husein. (2013), Riset Sumber Daya Manusia, Jakarta : Gramedia Pustaka Utama

Umar, Husein. (2005), Metode Penelitian, Jakarta : Salemba Empat

Umar, Husein. (2004), Metode Penelitian Untuk Skripsi dan Tesis Bisnis, Jakarta : PT. Raja Grafindo Persada

Wibowo. (2016), Manajemen Kinerja, Jakarta : PT. Rajawali Pers

Widoyoko. (2015), Teknik Penyusunan Instrumen Penelitian, Yogyakarta : Pustaka Pelajar

Wirawan. (2013), Kepemimpinan : Teori, Psikologi, Perilaku Organisasi, Aplikasi, dan Penelitian, Jakarta : PT. Raja Grafindo Persada

Tajarussalim, Pengaruh Pelatihan Terhadap Kinerja Pegawai Pada Inspektorat 
Kabupaten Rokan Hulu, Jurnal : Ekonomi dan Bisnis Volume 1 No 1 Tahun 2013.

Universitas Pasir Pengaraian

Kurniawati, Pengaruh Pelatihan Terhadap

Kinerja Pegawai di Kantor Balai Pelatihan

Cagar Budaya (BPCB) DIY, Jurnal :

Ekonomi dan Bisnis Volume 2 No 2

Tahun 2015. Universitas Telkom 